\title{
Estratégias de leitura usadas por alunos de Graduação e Mestrado de Educação
}

\author{
Reading strategies utilized by education students \\ to read prescribed study texts
}

\section{Elsa Maria Mendes Pessoa Pullin}

Doutorado em Psicologia Escolar e do Desenvolvimento Humano pela Universidade de São Paulo (IPUSP), professora associada na Universidade Estadual de Londrina (UEL), Londrina, PR - Brasil, e-mail: pullin@uel.br

\section{Resumo}

A leitura é um dos elementos essenciais para o exercício do ofício do aluno universitário. As metodologias mais comuns nos cursos de ensino superior pressupõem que o aluno nesse nível de escolarização disponha de uma metodologia individual e eficiente de leitura realizada com o objetivo de estudo. Com este trabalho teve-se o intuito de diagnosticar e comparar a frequência de uso de estratégias de leitura, consideradas fundamentais, quando esta é realizada para estudar. A escala de estratégias de leitura, traduzida e adaptada por Kopke Filho, foi o instrumento utilizado para a coleta de informações. Os dados foram coletados com dois grupos de alunas: um de um curso de Pedagogia $(n=10)$ e outro de um Mestrado em 
Educação $(n=10)$. De modo geral, as análises qualitativas e quantitativas realizadas permitem concluir que poucas são as diferenças estatisticamente significativas quanto à frequência de uso das estratégias de leitura por parte das participantes de cada grupo. Os resultados foram analisados e contrastados com os verificados em estudos anteriores, bem como assinalada a importância de os professores, em quaisquer que sejam os níveis de ensino em que atuem, estarem atentos e ensinarem modos de ler eficientes a seus alunos.

Palavras-chave: Leitura. Estratégias de leitura. Ensino superior.

\section{Abstract}

Reading is one of the essential elements for the exercise of the undergraduate student's occupation. The most common methodologies in undergraduate courses estimate that the student in this schooling level makes use of an individual efficient reading methodology accomplished with the objective of study. The aim of this research study was to diagnose and compare the frequency of reading strategies use, which are considered crucial, when reading is done with the purpose of study. The reading strategies scale, which was translated and adapted by Kopke Filho, was the instrument utilized for the information collection. The data were collected from two groups of registered students: one group in an undergraduate Pedagogy course $(n=10)$ and the other group in a Master Course on Education $(n=10)$. In general, the qualitative and quantitative analyses accomplished lead us to conclude that few are the statistically significant differences between the frequency of use of reading strategies by the participants of each group within both groups. The results were analyzed and contrasted with the ones verified in previous studies, as well as having emphasized the fact that teachers, in any teaching level and context, should be attentive to teaching efficient reading methods to their students.

Keywords: Reading. Reading strategies. Higher education.

\section{Introdução}

A importância da leitura é inquestionável para o exercício e a participação ativa dos cidadãos. Gimeno Sacristán (2008, p. 88), quando 
caracteriza o modelo cultural e educativo prevalecente orientado para a busca da formação humana, pondera: “[...] ler e escrever, o que está armazenado na escrita, o capacitar-se para lhe aceder e fazê-lo são aspectos culturais positivamente valorizados". Isso porque esse modelo "concede importância à ação e à atitude de se informar, à leitura como meio de se inserir no mundo enquanto seres reflexivos, continuando a aprender de forma autodidacta a partir do texto escrito [...]" (GIMENO SACRISTÁN, 2008, p. 89. sic).

Concordamos com esse autor quanto ao fato de que essa relevância se deve ao "valor instrumental que a leitura tem na vida das pessoas para participarem na sociedade do conhecimento [... o que] converte-a numa condição da cidadania e da inclusão social" (GIMENO-SACRISTÁN, 2008, p. 89).

No Brasil, apesar do aumento significativo das oportunidades educacionais, a população, de modo geral, está longe de atender às demandas socioeconômicas e às necessárias para o exercício pleno da cidadania, porque os níveis de escolaridade e de leitura de que dispõe (vide, por exemplo, os resultados do Indicador de Alfabetismo Funcional (INAF), analisados pelo Instituto Paulo Montenegro em 2009, não lhe facultam a condição de uma participação mais ativa e consciente (GOMES; BORUCHOVITCH, 2009).

Compete, especialmente à escola, ensinar os alunos a lerem os diferentes artefatos culturais, sejam os produzidos com o uso da escrita ou com o auxílio de outras tecnologias e instrumentos. Entretanto, são os textos produzidos por escrito os mais utilizados para a leitura no cotidiano escolar e os indicados para o aluno estudar. Em assim sendo, não é de estranhar que, desde cedo, especialmente essa leitura seja relacionada à escola e ao que nela se realiza e viabiliza com os saberes que nela se aprendem. As falas de crianças matriculadas no $1^{\circ}$ e no $2^{\circ}$ ano do ensino fundamental, no estudo conduzido por Gadelha e Carvalho (2007), assim o demonstram ao dizerem que ler serve para estudar, para fazer o dever direito e, algumas, ao evidenciarem a importância da leitura como uma forma de ser alguém na vida.

Estudar a partir de um texto exige uma série de atitudes e comportamentos por parte de quem assim o faz. A origem etimológica do 
termo estudo (studiu) aponta para dois deles: "aplicação zelosa, ardor" (FERREIRA, 1975, p. 589). Além disso, estudar "exige de quem o faz uma postura crítica sistemática. Exige disciplina intelectual que não se ganha a não ser praticando-a", como nos ensinou Paulo Freire (1982, p. 9). É uma leitura que ensina e com a qual se aprende (LARROSA, 2000), na medida em que o esforço para aprender só será coroado de êxito quando aquele que estuda aprende (MORGAN; DEESE, 1966).

Larrosa (2000) atribui o título Sobre a lição, a um dos seus capítulos, para expor o movimento de ensino e de aprendizagem que ocorre, ou deveria ocorrer, quando um professor propõe a seus alunos um texto para estudar. Ele compara essa ação do professor com a do envio de uma carta ou ao da entrega de um presente, visto que essa ação "não significa dar a ler o que se deve ler, mas sim 'dar a ler o que se deve: ler'. Ler não é um dever no sentido de uma obrigação, mas no sentido de uma dívida ou de uma tarefa" (LARROSA, 2000, p. 140, grifo do autor). Dívida e tarefa de quem recebe a leitura prescrita, que implica ações e movimentos específicos para realizá-la. Como, em parte, Paulo Freire (1982, p. 9) esclarece: "quem a recebe, por sua vez, deve ter nela, não uma prescrição dogmática de leituras, mas um desafio". Desafio esse que, quando aceito, instiga o leitor a se relacionar ativamente com o texto prescrito de um modo dialógico, proporcionando-lhe que se efetivem as condições necessárias para que se aproprie das informações que o texto apresenta, e ao assim proceder (re)elabore seus saberes.

De modo geral, os discursos oficiais que regulam a educação escolar brasileira, a saber, as diretrizes e os parâmetros curriculares para o ensino nos diversos níveis, têm proposto e justificado a necessidade da formação de leitores críticos. Contudo, no campo teórico, alguns colocam em questão o complemento, usado frequentemente para o verbo ler, especialmente quando ler vem seguido do qualificativo criticamente, como em Arena (2006). Isso porque ler é um verbo transitivo. Implica ações do leitor em relação ao texto, as quais dependem de múltiplos fatores, entre estes o dos efeitos criados pelo espaço histórico e situado de sua ocorrência (CAVALLO; CHARTIER, 1998), que se manifestam tanto no 
comportamento do leitor quanto no gênero textual utilizado pelo autor para produzir os enunciados do seu texto, bem como das finalidades e usos de quem o indicou.

O processo de construção de sentido(s) de um determinado texto depende, em suma e em parte, do leitor, especialmente das condições de diálogo que ele possa estabelecer com o texto, sendo estas parcialmente determinadas por sua experiência, pelo conhecimento prévio do mundo e por sua competência linguística (ECO, 1985). São essas condições que permitem ao leitor retirar "o texto da clandestinidade" (CORDEIRO, 2004, p. 97).

A leitura de textos recomendados para estudo, especialmente a prescrita para alunos universitários, tem atraído a atenção de pesquisadores (BARZOTO, 2005; CHARTIER, A.-M; DEBAYLE, J.; JACHIMOVICZ, M.-P., 1993; CREDÉ; KUNCEL, 2008; FRAISSE, 1993; PULLIN, 2006; 2007a, b, 2008; SILVA; SANTOS, 2004; VICENTELLI, 1999, 2004; WITTER, 1997; WITTER; VICENTELLI, 2001). Independente do enfoque teórico e das razões que orientam essas produções, o fato é que a temática tem atraído a atenção, e os resultados obtidos permitem, de modo geral, que se conclua que as práticas de leitura em instituições de ensino superior (IES) denotam relativa subvalorização e subutilização da leitura por parte dos estudantes universitários.

Contudo, as metodologias educacionais mais utilizadas no ensino superior, como as que pressupõem a participação dos alunos em discussões em sala de aula, em seminários, em distintas produções escritas, entre outras, exigem que eles realizem leituras. A produção dessas leituras é um dos elementos essenciais para o efetivo exercício do "ofício" do aluno universitário (PERRENOUD, 1995; WITTER, 1997; PAVÃO, 2002). Geralmente, o uso dessas metodologias tem por fundamento a crença dos professores quanto a que o aluno universitário já disponha de uma metodologia individual e eficiente de leitura realizada com o objetivo de estudo, o que nem sempre se verifica (VICENTELLI, 1999; PULLIN, 2006, 2007a, b). Isso porque uma das alternativas que o aluno tem para aprender é lendo; e, no diálogo que mantém com o texto, se desenvolver de modo autônomo, como efeito de suas "posturas 
argumentativas e críticas" (JOLY; PAULA, 2005, p. 33). Quando assim procede, aprende o que os textos ensinam e poderá (re)construir conhecimentos, especialmente os específicos e necessários para o seu exercício profissional futuro. Desse aluno se espera, enfim, que assuma, como "leitor-acadêmico" (DAUSTER, 2003), a posição de coautor, quando lê os textos que lhe são prescritos para as disciplinas do curso no qual deverá obter a sua graduação.

Com frequência, entretanto, são ignorados alguns dos obstáculos encontrados por esses alunos para lerem os textos indicados por seus professores. Desses obstáculos, os mais comuns têm sua origem em posturas e avaliações equivocadas de quem os prescreve, como nos explica Carlino (2003, p. 409): “o caráter implícito do conhecimento contido nos textos como as práticas leitoras, que os docentes consideram naturais (e não culturais), colocam obstáculos ao desenvolvimento de muitos estudantes". Outros obstáculos no desconhecimento, por parte dos alunos, vêm de quais sejam as estratégias mais eficientes para a leitura desses textos. Professores e alunos parecem ignorar que a leitura desses textos, no sentido de uma produção dialógica do leitor com esses gêneros textuais, exigem outras habilidades que ultrapassam as da decodificação. A constatação de déficits de habilidades eficazes para a leitura desses textos, por sua vez, informa que as oportunidades de terem sido iniciados nos processos de alfabetização científica (CARLINO, 2003) que esses textos exigem para sua leitura foram mínimas.

Reconhecendo, de um lado, que o vestibular tem permitido a entrada de alunos não suficientemente preparados para frequentar o ensino superior (OLIVEIRA, K. L. de; SANTOS, A. A. A. dos; PRIMI, R., 2003); e, de outro, o fato de que ao longo do curso os alunos sentem, com intensidade maior que a vivenciada em sua escolarização anterior, a necessidade de serem bons leitores, como nos lembra Oliveira (1993), não é de estranhar o relato, mesmo informal, de alunos que sentem dificuldades, impossibilidades e o fracasso em darem conta da quantidade de textos prescritos, ou por não adiantar ler, porque não os compreendem. Para muitos desses alunos, o tipo de texto, a quantidade e a frequência com que a leitura é prescrita 
para estudo configuram situações para as quais não foram preparados, pela escolarização anterior que usufruíram, para responder adequadamente (McNAMARA; HARBERSD, 2006; CARLINO, 2003).

O tipo de texto e a frequência exigida para que esses alunos leiam os textos de estudo indicados são situações novas para a maioria dos alunos universitários. Para que a leitura deles produza os efeitos desejáveis, os alunos precisam conhecer os termos técnicos específicos de cada campo disciplinar (CARLINO, 2003; PULLIN, 2007c), além da estrutura e dos recursos linguísticos admissíveis pela comunidade disciplinar na qual e para a qual o texto foi produzido.

Resultados de pesquisas, por exemplo, sobre o grau de compreensão em leitura obtido por alunos de distintos níveis de escolarização demonstram que as dificuldades não ocorrem apenas entre os do ensino fundamental e médio (OLIVEIRA et al., 2009a, b), mas também entre os de ensino superior (WITTER, 1997; CUNHA; SANTOS, 2006; TESSARO, 2004).

Paris, Lipson e Wixson (1983, apud KOPKE FILHO, 2001) distinguem o conceito de estratégia do de habilidades, indicando que o primeiro implica intencionalidade, isto é, um propósito por parte de quem age, bem como ser dele a escolha, consciente ou não, de uma entre as várias alternativas de que dispõe para se comportar. Essa condição de escolha é produto da histórica particular de cada indivíduo em situações similares ou específicas à que ele, em uma determinada situação e momento, deve interagir. Autores como Baker e Brown (1984 apud KOPKE FILHO, 2001) propõem a denominação de metacognição ao conhecimento e autocontrole da cognição por parte dos indivíduos. Por conseguinte, não é de se estranhar que as relações entre leitura, compreensão e metacognição venham despertando o interesse de diversos pesquisadores brasileiros, como reportado por Kopke Filho (2001, 2002), Rosenau (2005), Romanowski e Rosenau (2006), Pullin (2008a, b), Portilho (2009), entre outros.

Resultados de desempenho escolar de alunos matriculados nas séries finais do ensino fundamental e do ensino médio, como os publicados pelo MEC/SAEB (BRASIL, 2004), permitem concluir que poucos são os que adquiriram, após esses anos de escolarização, as competências 
definidas por essas provas para ser um bom leitor. Por exemplo, em 2003 os alunos de $8^{\mathrm{a}}$ série obtiveram a média mais baixa (232 pontos) na série histórica dessas avaliações realizadas a cada dois anos, desde 1995, enquanto os da $3^{\mathrm{a}}$ série do ensino médio apresentaram cinco pontos acima dos resultados da avaliação anterior, invertendo desse modo a tendência descendente dos resultados obtidos desde 1995.

Apesar de essa diferença não ser estatisticamente significativa, a média de pontos obtidos $(266,7)$ informa que o desempenho está aquém do indicador mínimo de proficiência prevista pelo instrumento (350 pontos) para o fim do ensino médio. Os que obtivessem em torno desse patamar seriam alunos que, segundo os proponentes desse modo de aferição, haviam consolidado "habilidades de leitura competente e condizente, tanto para a continuação de estudos quanto para o ingresso no mercado de trabalho qualificado" (BRASIL, 2004, p. 14). Cabe destacar que, apesar das queixas frequentes em relação ao desempenho dos alunos em Matemática, nas provas do SAEB as médias de desempenho em Português obtidas por esses alunos foram inferiores às obtidas em Matemática no período de 1999 a 2005 (BRASIL, 2004, 2007¹). Em face desses resultados, não causa estranheza o fato de alunos chegarem ao ensino superior com déficits de aprendizagem associados aos seus modos de ler.

Neste trabalho focaliza-se o comportamento de leitura de alunos universitários, especificamente quanto aos tipos de estratégias mais frequentemente (re)conhecidas como utilizadas por dois grupos de estudantes universitários: da graduação e da pós-graduação stricto sensu (mestrado), da área de Educação, de uma IES pública. Um projeto mais amplo ${ }^{2}$ inclui a participação de outros alunos e o uso de distintos instrumentos

${ }^{1}$ BRASIL, Ministério da Educação. Instituto Nacional de Estudos e Pesquisas Anísio Teixeira. SAEB 2005. SAEB 2005 - Primeiros resultados. Médias de desempenho do SAEB 2005 em perspectiva comparada. Brasília: INEP, 2007. Disponível em: <www.inep.gov.br/download/saeb/2005/SAEB 1999_2005.pdf >. Acesso em: 15 de março de 2008.

2 Projeto registrado na PROPPG da UEL, sob n. 04945, desenvolvido de 1/8/2007 a 31/3/2010. 
para caracterizar as funções atribuídas à leitura, memórias de suas formações como leitores, práticas e fontes de leitura. O presente relato é um recorte das informações colhidas nesse projeto mais amplo.

\section{O contexto e o processo de geração dos dados}

\section{Participantes}

Compuseram o corpo de participantes desta pesquisa dois grupos de alunos: dez matriculados na série inicial do curso de Pedagogia e dez frequentando o terceiro semestre do Mestrado de Educação, em 2007. Todas as participantes são do sexo feminino, com idades variando entre 18 e 42 anos e com experiência profissional que não ultrapassava um ano na educação infantil e no ensino superior, respectivamente em cada grupo.

As alunas de graduação (G1) frequentavam, quando da coleta, uma disciplina especial, isto é, complementar à sua formação profissional como pedagogas e para a qual a matrícula era facultativa. Essa disciplina, sob responsabilidade da pesquisadora, intitulava-se Leitura e Formação de Professores. As alunas do mestrado (G2) frequentavam a disciplina Leitura: Ensino e Aprendizagem, também sob a responsabilidade da pesquisadora.

\section{Material}

O instrumento utilizado foi a escala das estratégias de leitura (KOPKE FILHO, 2001), que instiga os respondentes a indicarem a frequência de uso das estratégias no processo/produção de leitura. Essa escala foi adaptada e traduzida por Kopke Filho (2001) a partir dos resultados de um estudo exploratório, com universitários, realizado dez anos antes por Goetz e Palmer. A escala compõe-se de 20 itens, distribuídos por três fases do processo/produção da leitura: previsão, isto é, antes de iniciada a leitura, composto por quatro itens; durante a produção de leitura propriamente 
dita, com dez itens; e após a leitura, restrita à avaliação dessa produção, com seis itens. Cada item da escala possibilita a escolha de uma entre cinco alternativas (sempre, frequentemente, às vezes, raramente, nunca).

Além dos espaços para a identificação, idade e indicação da experiência como professora, em qualquer nível de ensino, uma instrução solicitava aos participantes que ao responderem tivessem como foco textos propostos para estudo por seus professores.

\section{Procedimento}

Em sala de aula, após esclarecido o interesse e a importância de cada um refletir sobre as estratégias de leitura que utiliza para estudar, foi solicitada a colaboração de cada participante e a assinatura de um Termo de Consentimento Livre e Esclarecido. Após este ter sido recolhido, foi entregue a escala e destacado oralmente que deveriam ter em mente a leitura de textos recomendados para estudo, no curso em que se encontravam matriculadas. Não foi estipulado limite de tempo para responderem. Após todas terem devolvido a escala preenchida foi dado um intervalo.

$\mathrm{Na}$ aula seguinte, a pesquisadora caracterizou os fundamentos da escala, a importância de cada estratégia nela enunciada e apresentou, em slides, os resultados obtidos pelo grupo. O protocolo e o resultado individual foram entregues para que cada aluna pudesse analisar e comparar seu desempenho ao das demais. Ao longo dos três encontros subsequentes, esclarecimentos e discussões sobre os resultados obtidos pelo grupo foram realizados e foram informados dados de pesquisas similares, bem como ressaltada a importância dessas estratégias.

\section{Resultados e discussão}

Para o cômputo da frequência de uso das estratégias, identificada pela opção escolhida como resposta, foram usados os seguintes valores: 5 
para a opção sempre; 4 para frequentemente; 3 para às vezes; 2 para raramente; 1 para nunca. Em seguida, para uma configuração geral do uso das estratégias (re)conhecidas pelas participantes de cada grupo, tendo por foco a sua distribuição prevista pelo autor para o instrumento, foram calculadas as médias por etapa da leitura, conforme previstas pela escala. A Tabela 1 permite a visualização geral dos resultados obtidos, por grupo e participante.

Como se pode constatar, foram as participantes do G1 (graduação), independente da fase da realização da leitura, que indicaram utilizar com menos frequência as estratégias de leitura. As previsões e as hipóteses, consideradas por Cordeiro (2004, p. 97) como "recursos presentes na relação dialógica entre texto e leitor”, demonstram estar mais presentes

Tabela 1 - Médias individuais de uso das estratégias (média máxima = 5)

(Continua)

\begin{tabular}{lcccc}
\hline \multirow{2}{*}{ Participantes } & & \multicolumn{3}{c}{ Estratégias } \\
\cline { 3 - 5 } & & Antes & Durante & Após \\
\hline & P1 & 3 & 2,8 & 1,4 \\
& P3 & 1,7 & 2,5 & 1,7 \\
\hline G1 (Graduação) & 3 & 3 & 1,6 \\
& P4 & 2,7 & 3,3 & 1,9 \\
& P6 & 2,2 & 2,9 & 1,6 \\
& P7 & 1,7 & 2,7 & 1,5 \\
& P8 & 2,7 & 2,8 & 1,6 \\
& P9 & 1,7 & 3,3 & 2 \\
& P10 & 1,2 & 2,7 & 2,3
\end{tabular}


Tabela 1 - Médias individuais de uso das estratégias (média máxima = 5)

(Conclusão)

\begin{tabular}{lcccc}
\hline \multirow{2}{*}{ Participantes } & & \multicolumn{3}{c}{ Estratégias } \\
\cline { 3 - 5 } & & Antes & Durante & Após \\
\hline & P11 & 3,2 & 3,6 & 2 \\
& P12 & 2,2 & 3,2 & 2,3 \\
G2 (Mestrado) & 3,2 & 3,7 & 2,5 \\
& P14 & 3,2 & 3,5 & 2,4 \\
& P15 & 3,2 & 3,8 & 2,5 \\
& P16 & 3,7 & 3,9 & 2,5 \\
& P17 & 1,7 & 3 & 2,4 \\
& P18 & 3,2 & 3,6 & 2,3 \\
& P19 & 4,5 & 4,2 & 2,9 \\
& P20 & 2,2 & 2,9 & 2,1 \\
\hline
\end{tabular}

quanto ao uso geral de estratégias que as viabilizam entre as participantes do mestrado.

Contudo, se o exame inicial de textos parece ser feito frequentemente por todas as participantes do mestrado e apenas por algumas da graduação, após esse exame são as da graduação que mais frequentemente levantam hipóteses sobre o material a ser lido, enquanto apenas poucas do mestrado assim o fazem. O pensar a respeito da finalidade ou necessidade de realizar a leitura, isto é, estabelecer e ordenar metas a cumprir são comportamentos frequentes e comuns entre as participantes do G2 e para algumas do G1.

Ao longo da leitura, os grupos $\mathrm{G} 1$ e $\mathrm{G} 2$ revelam diferença quanto ao uso frequente das dez estratégias propostas para diagnosticar seus comportamentos. Distinguem-se principalmente quanto ao tomar notas, e ao refletirem, enquanto leem. Comparam-se às do G1 quanto ao pensarem acerca das 
implicações das informações do texto, sendo, porém, esse comportamento mais frequente nas participantes do G1, como pode ser visualizado na Tabela 1.

Considerando a leitura como um processo de produção de sentidos que "apenas se revela no movimento de idas e vindas entre texto e leitor" (CORDEIRO, 2004, p. 97), as estratégias de parar, refletir, reler o que não compreendeu e mesmo a de procurar fontes externas ao texto para compreendê-lo, enquanto o leem, são estratégias utilizadas frequentemente pelas participantes do G1. Esse processo de produção de sentidos, porém, também pode ser identificado após a leitura. Nesse caso, de modo geral, os movimentos de leitura do G2 são bastante diferentes daqueles do G1, como pode ser visualizado pela Tabela 1 .

Compete assinalar que apesar de poucas participantes do G2 (mestrado) terem assinalado que frequentemente levantam hipóteses sobre o texto a ser lido, mesmo que algumas informem que após a leitura verificam se as hipóteses são ou não confirmadas, as da graduação (G1) o fazem ocasionalmente e ou raramente.

Para verificar possíveis correlações entre as frequências de uso das estratégias, os dados foram submetidos ao teste Spearman, no programa STA, tendo-se definido como critério de aceite para significação $p<0,05$. Foi constatado um total de 75 correlações significativas que se distribuíram no intervalo de $-0,48$ a 0,90.

As quatro estratégias previstas no instrumento para serem usadas antes de iniciada a leitura propriamente dita mantêm relações significativas entre si que variam de 0,64 a 0,90 . As relações mais fortes foram registradas entre a estratégia de examinar a estrutura do texto lendo cabeçalhos, títulos e subtítulos, e a de examinar rapidamente o texto (Est1XEst2 $=0,90^{*}$ ), seguida pela relação entre examinar o texto e a de levantar hipóteses acerca de seu conteúdo (Est1XEst3 $=0,81^{*}$ ).

De modo geral, a frequência de uso das estratégias arroladas na escala utilizada para serem usadas antes da leitura do texto propriamente dita relacionam-se significativamente com 19 das previstas para ocorrerem durante e após a leitura realizada. Tais relações variam de $-0,48^{*}$ a $0,71^{*}$. A indicação de uma relação negativa, quando analisada estatisticamente a 
força entre duas variáveis, sugere que o aumento em uma é acompanhado pela outra, porém em sentido inverso. Isso foi registrado no resultado da relação entre a frequência de uso da estratégia de levantar hipóteses acerca do texto, após um exame breve deste, e a de quando não compreende uma palavra, frase ou parágrafo voltar a lê-los (Est3XEst11 = -0,48*). Apesar de o valor obtido ser pequeno, instiga mais o fato do sentido da relação, isto é, o de ser negativo. Dessas relações, as positivas e mais fortes observadas foram entre a de examinar a estrutura do texto, lendo cabeçalhos, títulos, subtítulos, etc. e a de, quando lê, pensar a respeito das implicações do que o texto apresenta (Est2XEst9 $=0,71^{*}$ ) com a de parar a leitura para refletir se está compreendendo ou não o que lê (Est2XEst10 =0,71*).

As frequências de uso das quatro estratégias previstas para serem usadas antes de realizada a leitura propriamente dita do texto relacionam-se com apenas duas das seis elencadas para ocorrerem depois de finalizada a leitura. No caso Est 1, Est2, Est3 e Est4, com as de verificar se as hipóteses que levantou acerca do conteúdo do texto se confirmam ou não (Est19) e com a de procurar produzir uma paráfrase ou resumo do texto (Est2 e Est3XEst20).

Das estratégias previstas para acontecerem durante a leitura propriamente dita do texto, registramos que 27 relacionam-se significativamente entre si, demonstrando uma variação dessa significância entre 0,51* e 0,67*. Essas foram observadas entre a estratégia de tomar notas (Est6) e a de, ao lerem, relacionarem as informações do texto com suas crenças e conhecimentos anteriores (Est8) 0,60*, pensar a respeito das implicações do que o texto apresenta (Est 9) 0,67*, pararem e refletirem se estão compreendendo o que leem (Est10) 0,58*, a de buscarem reler as partes que precedem os trechos não compreendidos (Est12) 0,64*, e a de prosseguir a leitura para tentarem compreender algum trecho (Est13) 0,52*. Das demais correlações merecem destaque, pela força da relação verificada, as observadas entre pensar a respeito das implicações das informações do texto com a de parar e refletir se compreende o que está lendo (Est9XEst10 =0,67*), com a de reler o que não está compreendo (Est9XEst11 =0,67*), além das constatadas entre a estratégia de relacionar as informações do texto com 
suas crenças e conhecimentos prévios com a de continuar a leitura em busca de compreender o que não compreendeu (Est8XEst13 = 0,62*).

As estratégias arroladas para ocorrerem após ter-se concluído a leitura mantêm relações entre si que variam significativamente no intervalo de 0,52 a 0,74. Destas, as mais fortes foram registradas entre a de procurar relembrar os pontos fundamentais do texto sem a ele voltar e a de fazer paráfrase ou resumos do texto (Est17XEst20 $=0,73^{*}$ ), com a de fazer uma releitura (Est15) 0,64*, e com a de avaliar o quanto não entendeu ao ler o texto voltando a reler as partes em que se sente inseguro (Est15) $0,64^{*}$. As relações mais fortes $\left(0,74^{*}\right)$ entre as estratégias previstas para acontecerem após concluída a leitura foram verificadas entre a estratégia de procurar produzir uma síntese ou paráfrase do que leu (Est20) com a de verificar se as hipóteses que construiu antes de ler se confirmam ou não (Est19).

A Tabela 2 permite a visualização das correlações obtidas entre a frequência de uso das estratégias por parte das participantes $(G 1+G 2)$. Observese que, segundo a proposição dos autores da escala, as estratégias 1 a 4 correspondem à etapa antes da leitura, a saber, à do encontro do leitor com o texto; as estratégias 5 a 14, às previstas para a etapa durante a realização propriamente dita da leitura do texto; e as estratégias 15 a 20 para a etapa após essa concluída.

Sendo essas as relações constatadas entre a frequência de uso das estratégias de leitura (re)conhecidas por alunas de um curso de Pedagogia e de um Mestrado em Educação, resta-nos analisar se o uso das mesmas se diferencia ou não entre elas. Para tanto, foi utilizado o Teste $U$ de Mann-Whitney e definido o valor de $\mathrm{p}<$ 0,05 para o estabelecimento da significância.

Das estratégias propostas pela escala para uso do leitor antes da realização da leitura propriamente dita do texto foram registradas diferenças significativas entre os dois grupos, quanto às frequências de uso das estratégias de examinar a estrutura geral da composição do texto (Est2) e a de levantar hipóteses acerca do conteúdo a ser lido, ambas favoráveis ao GM. Nas demais estratégias (1 e 4), a saber, a de examinar rapidamente todo o texto e na de pensar a respeito da finalidade ou necessidade de realizar a leitura, as diferenças intergupos não foram significativas, 


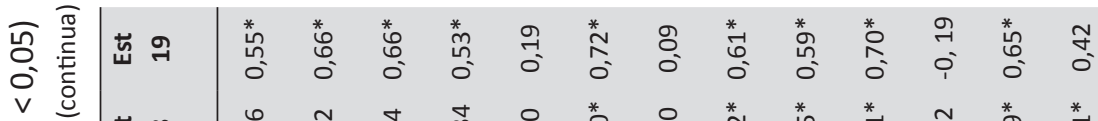

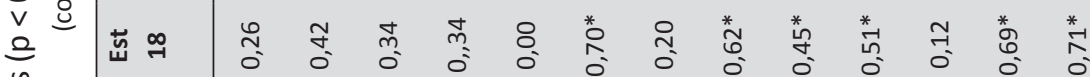

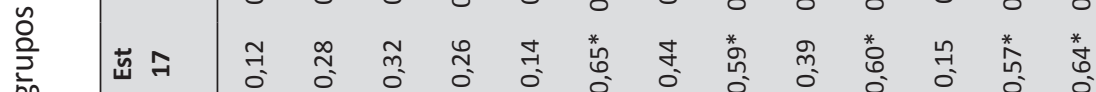

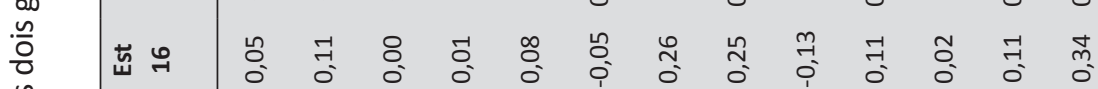

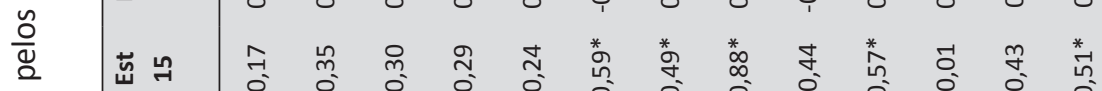

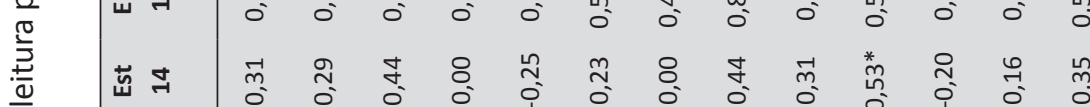

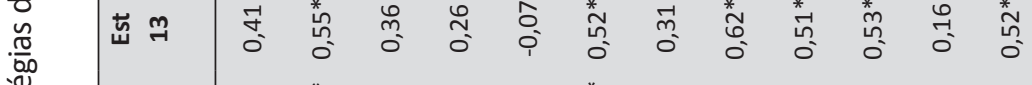

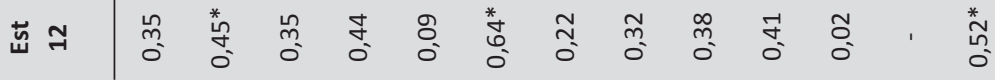

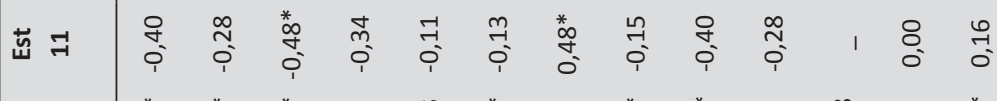

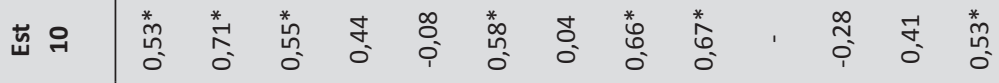

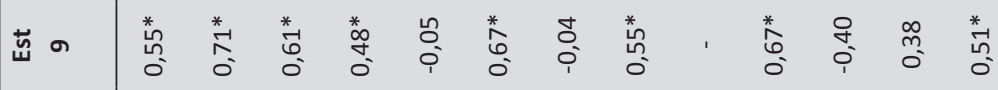

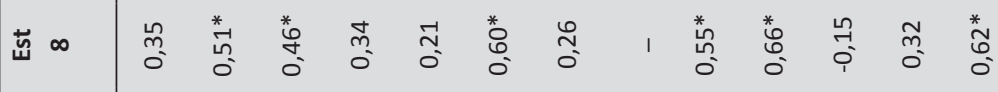

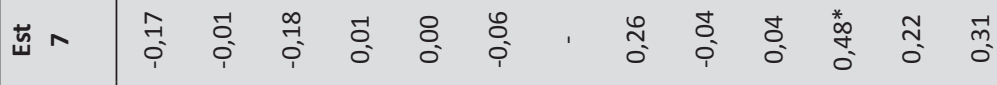

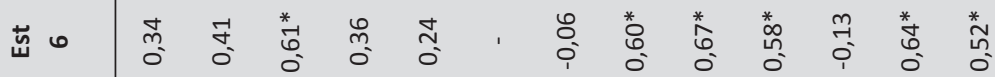

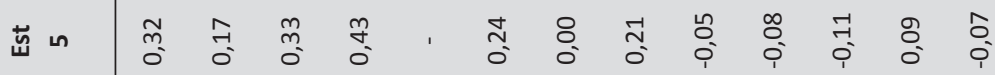

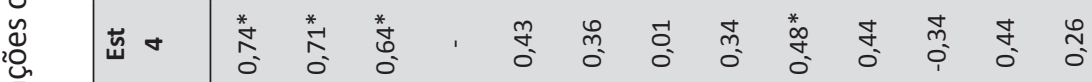

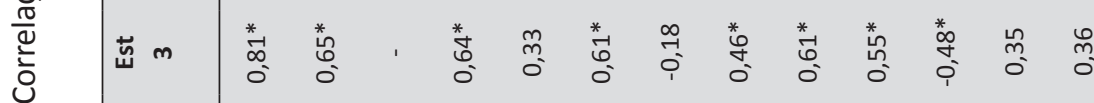

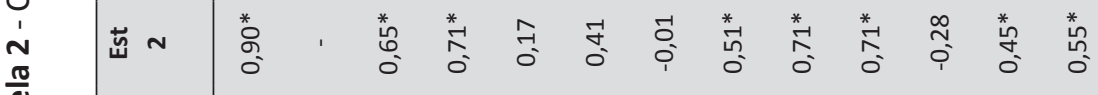

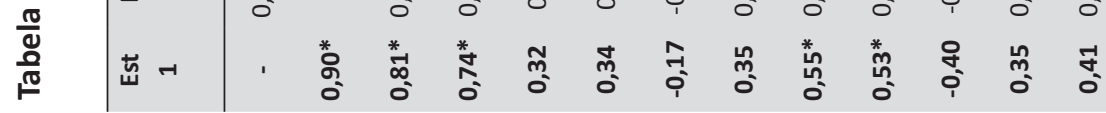




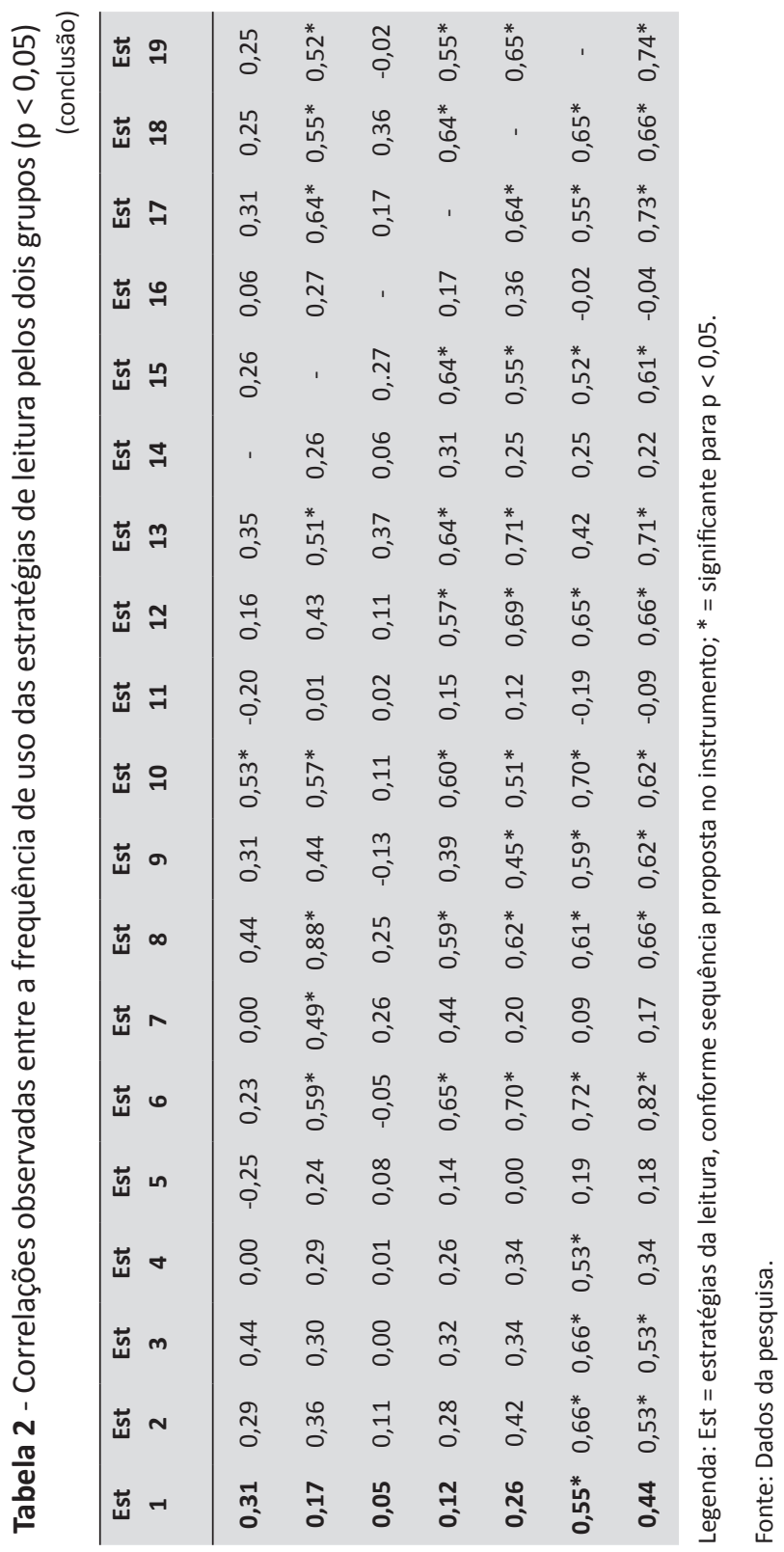


apesar de demonstrarem que as participantes do GM utilizam com maior frequência do que as do GG.

Das estratégias arroladas para utilização do leitor durante a leitura, apenas três não diferenciam significativamente a frequência de seu uso entre os grupos: as estratégias de sublinhar as ideias ou as palavras principais (Est5), a de criar imagens mentais de conceitos ou fatos descritos no texto e a de consultar uma fonte externa quando não compreende uma palavra, frase ou parágrafo (Est14). A Est5, apesar de ser mais utilizada pelas participantes do GG (soma dos postos $=112,50$ contra 97,50 do $\mathrm{GM}$ ) e a Est14 pelo GM (soma dos postos $=123,5$, contra 86,50 do GP), as diferenças constatadas não foram significativas. A análise comparativa (GGXGM), quanto ao uso das demais estratégias durante a leitura, confirma que não só as diferenças são significativas entre os grupos e favoráveis ao GM quanto são significativas a níveis mais baixos do que o estipulado $(\mathrm{p}<0,05)$.

Concluída a leitura do texto, quatro estratégias são arroladas no instrumento. As respostas das participantes, indicativas da frequência do uso dessas estratégias, isto é, das Est. 15 a Est20 apontam para diferenças significativas entre GM e GG, exceto quanto à Est. 16, qual seja, a de voltar ao texto e reler os pontos mais relevantes. Contudo, nestas quanto nas demais estratégias previstas para após a leitura, os resultados demonstram que as participantes do GM usam com mais frequência essas estratégias do que as do GG.

Interessante são os resultados que não diferenciam significativamente os dados do GG e do GM. Resultados similares foram registrados por Vicentelli (1999). No presente estudo, as participantes de ambos os grupos examinam o texto que devem ler para estudo e pensam a respeito da finalidade ou necessidade de realizarem a leitura antes de lê-lo. Entretanto, como informado, um exame mais cuidadoso do texto (Est2) e a proposição de hipóteses acerca do seu conteúdo (Est3) diferenciam significativamente o GG do GM. O recurso de sublinhar o que considera como importante (Est5), a busca de auxílio externo quando não compreende enquanto está lendo (Est14), e a de retornar ao texto para reler os pontos mais relevantes (Est16) são estratégias de uso comum e que não diferenciam GG de GM. 
As condições previstas por Castilho (1999) para alguém se tornar um leitor eficiente, pelos perfis de leitura traçados pelos resultados obtidos pelas participantes deste estudo, parecem longe de terem sido oportunizadas, visto que nos dois grupos raramente foi registrado que ao lerem sempre o façam para: atingir um propósito; consigam interagir com o texto ativando os conhecimentos prévios; compreendam significativamente e facilmente o conteúdo que leem; apresentem uma atitude crítica em relação ao texto lido.

\section{Considerações possíveis}

Os resultados obtidos no presente trabalho se assemelham com os assinalados na literatura pertinente. Os alunos chegam ao ensino superior sem possibilidades de lerem a contento os textos de estudo que lhes são prescritos. Apesar da "dimensão capital da formação inicial" (CHARTIER, 1999, p. 93), obtida em cursos de graduação, pouco tem sido investido no sentido de uma alfabetização que propicie a leitura efetiva dos textos científicos prescritos, como defendido por Carlino (2003) e Pullin (2007c). Por isso, mínimas são as diferenças significativas registradas nos modos de ler quando comparados alunos que iniciam sua formação nesse nível de ensino e os que estão mais avançados (VICENTELLI, 1999), como também demonstram os resultados colhidos neste estudo.

Concordamos com Anne-Marie Chartier (1999, p. 96) quanto à necessidade dos educadores estarem atentos às

formas pelas quais a leitura (o que é lido e as maneiras de ler) se integra na preparação da profissão, [visto que por elas] transmite-se de forma concreta uma relação com o escrito como ferramenta de trabalho profissional, como espaço de cultura pessoal, como referente compartilhado.

Autores como Silva (1998; 1999; 2003), Batista (1998), Britto (1998), Garcia (1998), Freitas e Costa (2002) vêm dedicando-se há anos 
às temáticas da leitura e à relevância desta para a formação de professores, dado que eles, por razões de ofício, desempenham papéis importantes na formação de novos leitores. Tanto uns quanto outros precisam ser capacitados a ler os múltiplos e distintos artefatos culturais, de modo que possam adquirir e analisar criticamente os conhecimentos já produzidos e, ao assim procederem, exercerem efetivamente sua cidadania (GIMENO SACRISTÁN, 2008).

Esse exercício se efetivará, especialmente, quando os educadores dos diferentes níveis de ensino viabilizarem as condições necessárias para que cada um dos seus alunos possa estar e ser, nas relações que venha a manter com o que o rodeia, imbuído do espírito de um eterno estudante. Espírito este caracterizado por Larrosa (2000), pelos seguintes traços: amplitude indeterminada de curiosidade, alegria inocente dos descobrimentos, vitalidade apaixonada pelas perguntas, atrevimento ousado nas afirmações, parcialidade sem complexos de seus gostos, segurança quanto à incompletude e provisionalidade dos resultados e de suas conclusões.

Os resultados deste estudo sugerem algumas implicações para o ensino, avaliação e pesquisa. Ao indicarem que as estratégias de leitura de textos de estudo reportadas pelas participantes (alunas recém-ingressas no curso de Pedagogia e de um Mestrado em Educação) são distintas e, algumas delas, utilizadas ocasionalmente, sinalizam para a importância de os professores estarem atentos, quando prescrevem e discutem as leituras realizadas, bem como a encontrarem modos de incorporar em suas metodologias a possibilidade de ensinar os alunos a utilizá-las com mais frequência.

Esses resultados apresentam, também, implicações para a avaliação das estratégias de leitura utilizadas por estudantes, quando leem textos de estudo. O instrumento utilizado neste trabalho é útil para alunos e para professores. Para respondê-lo, os alunos precisam pensar acerca dos modos e frequência com que usa essas estratégias. Além disso, poderia ser utilizado como roteiro para a análise posterior das ações relatadas oralmente, pelo aluno para o professor/pesquisador, de como realiza sua leitura quando seleciona um texto para estudar na medida em que o lê. Os movimentos em direção à metacognição desses comportamentos 
poderiam assim ser desencadeados, pela simples aplicação, ou acoplada a outras, como exemplificado.

O instrumento utilizado neste estudo, a escala de estratégias de leitura, de Goetz e Palmer, é um exemplo dos reportados na literatura pertinente, especificamente na estrangeira. Sua tradução e adaptação para o Brasil, realizada por Kopke Filho (2001), tem viabilizado a realização de investigações não só exploratórias como de intervenção (KOPKE FILHO, 2001, 2002; PULLIN, 2006, 2007a, b, 2008; PULLIN; MOREIRA, 2008). Infelizmente, essa escala, como outros instrumentos utilizados por pesquisadores estrangeiros, ainda não foi validada para a população brasileira e menos ainda para ser aplicada a alunos universitários. Por conseguinte, muito há ainda que ser feito.

\section{Referências}

ARENA, D. B. Considerações sobre o estatuto de leitor crítico. In: BARBOSA, R. L. L. (Org.). Formação de educadores: artes e técnicas, ciências e políticas. São Paulo: Ed. UNESP, 2006. p. 409-422.

BARZOTTO, V. H. Estado da leitura. Campinas: Mercado de Letras; Associação de Leitura do Brasil, 1999.

BATISTA, A. G. Os professores são 'não-leitores'? In: MARINHO, M.; SILVA, C. S. R. da. (Org.). Leituras do professor. Campinas: Mercado de Letras, 1998. p. 23-60.

BRASIL. Ministério da Educação. Resultados do SAEB 2003: versão preliminar. Brasília: MEC, 2004.

BRITTO, L. P. Leitor interditado. In: MARINHO, M.; SILVA, C. S. R. da. (Org.). Leituras do professor. Campinas: Mercado de Letras, 1998. p. 61- 78.

CARLINO, P. Alfabetización académica: un cambio necesario, algunas alternativas posibles. Educere, Mérida v. 6, n. 20, p. 409-420, 2003. 
CASTILHO, H. V. A leitura e textos literários VS textos científicos por leitores incipientes. In: WITTER, G. P. (Org.). Leitura, textos e pesquisas. Campinas: Alínea, 1999. p. 55-64.

CAVALLO, G.; CHARTIER, R. História da leitura no mundo ocidental. São Paulo: Ática, 1998.

CHARTIER, A.-M. Os futuros professores e a leitura. In: BATISTA, A. A. G.; GALVÃO, A. M. de O. (Org.). Leitura: práticas, impressos, letramento. Belo Horizonte: Autêntica, 1999. p. 89-97.

CHARTIER, A.-M.; DEBAYLE, J.; JACHIMOWICZ, M.-P. Lectures pratiquées et lectures déclarées: reflexions autour d' une enquête sur les étudiants en IUFM. In: FRAISSE, E. (Org.). Les étudiantes et la lecture. Paris: Presses Universitaires de France, 1993. p. 73-98.

CORDEIRO, V. M. R. Itinerários da leitura no espaço escolar. Educação \& Contemporaneidade, Salvador, v. 13, n. 21, p. 95-102, 2004.

CREDÉ, M.; KUNCEL, N. R. Study habits, skills, and attitudes: the third pillar supporting collegiate academic performance. Perspectives on Psychological Science, v. 3, n. 6, p. 425-453, 2008.

CUNHA, N. de B.; SANTOS, A. A. A. dos. Relação entre a compreensão da leitura e a produção escrita em universitários. Psicologia: Reflexão e Crítica, Porto Alegre, v. 19, n. 2, p. 118-124, 2006.

DAUSTER, T. A invenção do leitor acadêmico: quando a leitura é estudo. Leitura: Teoria e Prática, Campinas, n. 41, p. 73-83, 2003.

ECO, U. Lector in Fabula. São Paulo: Perpectiva, 1985.

FERREIRA, A. B. de H. Novo dicionário da língua portuguesa. Rio de Janeiro: Nova Fronteira, 1975

FRAISSE, E. Les chemins de la lecture à l'université. In: FRAISSE, E. (Org.). Les étudiants et la lecture. Paris: Presses Universitaires de France, 1993. p. 241-252. 
FREIRE, P. Considerações em torno do ato de estudar. In: FREIRE, P. Ação cultural para a liberdade e outros escritos. 6. ed. Rio de Janeiro: Paz e Terra, 1982. p. 9-12.

FREITAS, M. T. A.; COSTA, S. R. Leitura e escrita na formação de professores. Juiz de Fora: UFIF, 2002.

GADELHA, M. J. de A.; CARVALHO, M. do R. de F. de. Ler serve prá estudar: representações sociais das crianças do ensino fundamental. In: JORNADA INTERNACIONAL, 5., e CONFERÊNCIA BRASILEIRA SOBRE REPRESENTAÇÕES SOCIAIS, 3., 2007, Brasília. Anais... Brasília: Universidade de Brasília, 2007. p. 1-12.

GARCIA, R. L. (Org.). A formação da professora alfabetizadora: reflexões sobre a prática. 2. ed. São Paulo: Cortez, 1998.

GIMENO SACRISTÁN, J. Com que ferramentas entram nossos alunos na sociedade da informação? In: GIMENO SACRISTÁN, J. A educação que ainda é possível: ensaios sobre a cultura para a educação. Porto: Portoed, 2008. p. 85-109.

GOMES, M. A. M. dos; BORUCHOVITCH, E. Proficiência em leitura: um panorama da situação. In: SANTOS, A. A. A. dos S.; BORUCHOVITCH, E.; OLIVEIRA, Katya L. de O. Cloze: um instrumento de diagnóstico e intervenção. São Paulo: Casa do Psicólogo, 2009. p. 23-46.

JOLY, M. C. R. A.; PAULA, L. M. Avaliação do uso de estratégias de aprendizagem e a compreensão em leitura de universitários. In: JOLY, M. C. R.; SANTOS, A. A. dos. (Org.). Questões do cotidiano universitário. São Paulo: Casa do Psicólogo, 2005. p. 33-57.

KOPKE FILHO, H. Estratégias em compreensão da leitura: conhecimento e uso por professor de língua portuguesa. 2001. $148 \mathrm{f}$. Tese (Doutorado em Lingüística) - Faculdade de Filosofia Ciências e Letras, Universidade de São Paulo, São Paulo, 2001.

KOPKE FILHO, H. Repertório de estratégias de compreensão da leitura e conhecimento metacognitivo de professores da língua portuguesa. Psicologia Escolar e Educacional, Campinas: ABRAPEE, v. 6, n. 1, p. 67-80, 2002. 
LARROSA, J. Sobre a lição. In: LARROSA, J. Pedagogia profana: danças, piruetas e mascaradas. 3. ed. Belo Horizonte: Autêntica, 2000. p. 139-146.

McNAMARA, D. S; HARBERSD, H. Reading skills of students at-risk for academic failure in high school. Disponível em: <www.speechpathology.com/articles/ article_detail.asp?article_id=216 >. Acesso em: 13 abr. 2006.

MORGAN, C. T.; DEESE, J. Como estudar. Rio de Janeiro: Freitas Bastos, 1966.

OLIVEIRA, M. H. M. A. A leitura do universitário: estudo comparativo entre os cursos de Engenharia e Fonoaudiologia da PUCCAMP. 1993. 113 f. Dissertação (Mestrado em Psicologia Escolar) - Universidade Estadual de Campinas, Campinas, 1993.

OLIVEIRA, K. L. de; SANTOS, A. A. A. dos; PRIMI, R. Estudo das relações entre compreensão em leitura e desempenho acadêmico na universidade. Interação em Psicologia, Curitiba, v. 7, n. 1, p. 19-25, 2003.

OLIVEIRA, K. L. de; BORUCHOVITCH, E.; SANTOS, A. A. A. dos. Leitura e desempenho escolar em alunos do ensino fundamental. In: SANTOS, A. A. A. dos; BORUCHOVITCH, E.; OLIVEIRA, K. L. de. Cloze: um instrumento de diagnóstico e intervenção. São Paulo: Casa do Psicólogo, 2009a. p. 149-164.

OLIVEIRA, K. L. de; CANTALICE, L. M. de; FREITAS, F. A. Compreensão em leitura no ensino médio: análise de acertos por item. In: SANTOS, A. A. A. dos; BORUCHOVITCH, E.; OLIVEIRA, K. L. de. Cloze: um instrumento de diagnóstico e intervenção. São Paulo: Casa do Psicólogo, 2009b. p. 165-185.

PAVÃO, A. A fotocópia como instituição pedagógica. In: REUNIÃO ANUAL DA ANPED, 25., 2002. Caxambu - MG. Anais... Caxambu: ANPED, 2002.

PERRENOUD, P. Ofício de aluno e sentido do trabalho escolar. Porto: PortoEd, 1995.

PORTILHO, E. M. L. Como se aprende? Estratégias, estilos e metacognição. Rio de Janeiro: WAK, 2009. 
PULLIN, E. M. M. P. Relatório parcial do projeto de pesquisa: metacognição, práticas de leitura e estratégias de estudo em estudantes de um curso de formação de professores: possíveis efeitos de um programa de intervenção, apresentado à PROPPG da UEL. 2008. Manuscrito.

PULlin, E. M. M. P. EDUCAÇÃO - EDUCERE, 6., 2006, Curitiba. Anais... Curitiba: Champagnat, 2006. p. 980-992.

PULLIN, E. M. M. P. Leitura de estudo: estratégias reconhecidas como utilizadas por alunos universitários. Ciências \& Cognição, Rio de Janeiro, v. 12, p. 51-61, 2007a.

PULLIN, E. M. M. P.; PULLIN, A. M. P. Leitura de alunas de um mestrado em educação: implicações para o ensino e pesquisa. In: CONGRESSO ESTADUAL PAULISTA SOBRE FORMAÇÃO DE EDUCADORES - MODOS DE SER EDUCADOR: ARTES E TÉCNICAS, CIÊNCIAS E POLÍTICAS, 8., 2007, São Paulo. Anais... São Paulo: UNESP, 2007b. p. 28-38.

PULLIN, E. M. M. P. Textos técnico-científicos como objetos culturais de difícil acesso a universitários. In: CONGRESSO DE LEITURA DO BRASIL (COLE), 16., 2007, Campinas. Anais... Campinas: Unicamp/ALB, 2007c. p. 373-374.

PULLIN, E. M. M. P.; MOREIRA, L. de S. G. Prescrição de leitura na escola e formação de leitores, Ciências \& Cognição, Rio de Janeiro, v. 13, n. 3, p. 231-242, 2008.

ROMANOWSKI, J. P.; ROSENAU, L. dos S. A contribuição dos processos metacognitivos na formação do pedagogo. Intersaberes, Curitiba, v. 1, n. 1, p. 1-19, 2006.

SILVA, E. T. da. Elementos de pedagogia da leitura. São Paulo: M. Fontes, 1998. SILVA, E. T. da. De olhos abertos: reflexões sobre o desenvolvimento da leitura no Brasil. São Paulo: Ática, 1999.

SILVA, E. T. da. Leitura em curso: triologia pedagógica. Campinas: Autores Associados, 2003. 
SILVA, M. J. M. da; SANTOS, A. A. A. dos. A avaliação da compreensão em leitura e o desempenho acadêmico de universitários. Psicologia em Estudo, Maringá, v. 9, n. 3, p. 459-467, 2004.

TESSARO, N. S. Leitura na vida de universitários: estudo comparativo entre instituições de ensino superior. In: WITTER, G. P. (Org.). Leitura e psicologia. Campinas: Alínea, 2004. p. 45-75.

VICENTELLI, H. Problemática de la lectura en estudiantes universitarios. Psicologia Escolar e Educacional, Campinas, v. 3, n. 3, p. 195-202, 1999.

VICENTELLI, H. La universidad como agente promotor de la lectura, en el contexto de la sociedad venezolana. Psicologia Escolar e Educacional, Campinas, v. 8, n. 1, p. 29-33, 2004.

WITTER, G. P. Leitura e universidade. In: WITTER, G. P. (Org.). Psicologia: leitura e universidade. Campinas: Alínea, 1997. p. 9-18.

WITTER, C. P.; VICENTELLI, H. Lectura y universidad. Revista Comportamiento, Caracas, v. 5, p. 57-73, 2001.

Recebido: 09/02/2011

Received: 02/09/2011

Aprovado: 13/04/2011

Approved: 04/13/2011 